\title{
An Improved Transfection Assay for Evaluating the Effects of Heavy Metals
}

\author{
Kaoru SUZUKI ${ }^{1}$ and Shinji KOIZUMI* ${ }^{1 *}$
}

\author{
${ }^{1}$ Human Engineering and Risk Management Research Group, National Institute of Occupational Safety and \\ Health, 6-21-1 Nagao, Tama-ku, Kawasaki 214-8585, Japan
}

Received October 10, 2008 and accepted March 12, 2009

\begin{abstract}
The transfection assay is an important tool for evaluating the health effects of industrial chemicals, with the reporter gene expression as an indicator. However, heavy metals often influence the expression of the reference plasmids used to correct variations in transfection efficiency between assay plates, reducing the reliability of this assay. We found that the target of heavy metals is the reporter, rather than the promoter used in the reference plasmid. Of the reporters we tested, luciferase (Luc) enzyme activity was affected by heavy metals, whereas gene product levels of the chloramphenicol acetyltransferase (CAT) or $\beta$-galactosidase ( $\beta$ Gal) gene were not. Neither heavy metals nor extracts from cells exposed to heavy metals showed an effect when directly added to the Luc enzyme, suggesting that heavy metals act through an indirect mechanism. These data indicate that the use of CAT or $\beta \mathrm{Gal}$ as a reporter is appropriate for a reliable assay of heavy metal effects.
\end{abstract}

Key words: Transfection assay, Heavy metal, Zinc, Cadmium, Human cells, Health effects

The transient transfection assay is now an important tool for assessing the health effects of chemicals, with the reporter gene expression level as an indicator ${ }^{1)}$. The performance of this assay was very impressive when it was frequently used to estimate endocrine disruptor activity several years ago. This method is potentially useful for evaluating the effects of a wider range of chemicals. It is particularly advantageous for evaluating the effect on a definite gene regulation process, and also for analyzing the mechanism of action. In addition, the recent progress of biotechnology has been making this assay more convenient to use.

Heavy metals form a category of industrial chemicals exerting detrimental effects on the health of workers. It is also known that heavy metals affect the transcription of many genes ${ }^{2,3)}$. We have applied the transient transfection assay to the analysis of heavy metal effects on several human genes, including those coding for metallothionein ${ }^{4)}, 70 \mathrm{kDa}$ heat shock protein ${ }^{5)}$ and heme oxygenase-16). However, in the course of those studies we encountered a problem. In transient transfection assays, a "reference plasmid" is usually co-transfected together

*To whom correspondence should be addressed. with a "reporter plasmid". The expression level of the reporter gene carried in the reporter plasmid is then normalized to that of the reporter gene carried in the reference plasmid to correct differences in transfection efficiency between culture plates. Therefore it is a prerequisite that reporter expression from the reference plasmid should be constant either in the presence or absence of the chemicals to be tested. Nevertheless, it has been observed that heavy metals often affect reporter expression from a reference plasmid ${ }^{7}$, reducing the reliability of the assay. In the present work, we inspected assay conditions in order to find a way to circumvent this problem.

In the transient transfection assay, we have usually used a reference plasmid, pRSV-Luc, which carries the firefly luciferase (Luc) gene ${ }^{8)}$ driven by the Rous sarcoma virus long-terminal repeat (RSV-LTR) promoter (Fig. 1) ${ }^{4}$. We have observed that Luc expression is not changed by exposure to $100 \mu \mathrm{M} \mathrm{Zn}$, but is increased by $\mathrm{Cd}$ ( 2 or $20 \mu \mathrm{M})$ or a higher concentration of $\mathrm{Zn}(200 \mu \mathrm{M})^{7)}$. Because some gene promoters frequently used in reference plasmids have been reported to be affected by heavy metals ${ }^{9,10)}$, we initially tried to find a promoter with constant activity irrespective of the presence or absence of 


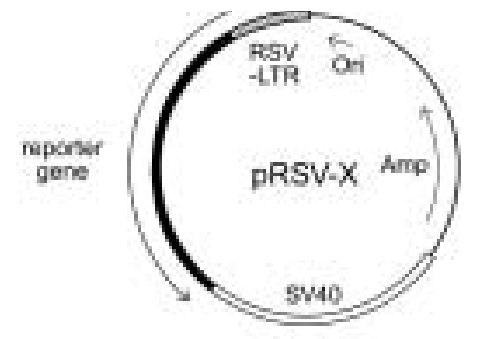

PREVLUD reporter $=$ lucferase

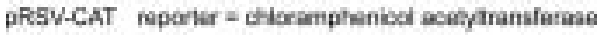

plesV-j|Gal reporter = p-gsiactusidase

Fig. 1. Plasmids used in transient transfection assays.

heavy metals. We tested several other promoters including those from the herpesvirus thymidine kinase, adenovirus major late and $\beta$-actin genes, using Luc as a reporter. However, all these promoters were also observed to be influenced by heavy metals (data not shown).

Based on these results, we then examined whether the Luc gene is appropriate as a reporter gene in metal experiments. The Luc gene was compared with two other genes coding for $E$. coli chloramphenicol acetyltransferase $(\mathrm{CAT})^{11)}$ and $\beta$-galactosidase $(\beta \mathrm{Gal})^{12)}$, with regard to the response to heavy metals under the control of the same RSV promoter. Plasmids with alternative reporter genes were constructed by replacing the Luc gene, positioned just downstream of the RSV promoter in pRSV-Luc, with the CAT or $\beta$ Gal gene, generating pRSV-CAT and pRSV$\beta \mathrm{Gal}$, respectively (Fig. 1). Human HeLa cells were plated in $60-\mathrm{mm}$ plastic dishes (Falcon) containing Eagle's minimum essential medium supplemented with $10 \%$ calf serum and non-essential amino acids, and incubated for $24 \mathrm{~h}$ at $37^{\circ} \mathrm{C}$ under a $5 \% \mathrm{CO}_{2}$ atmosphere. Cells were transfected with pRSV-Luc $(4 \mu \mathrm{g})$ or an equimolar amount of pRSV-CAT or pRSV- $\beta$ Gal by the standard calcium-phosphate transfection method and incubated for a further $28 \mathrm{~h} . \mathrm{CdSO}_{4}$ or $\mathrm{ZnSO}_{4}$ was added to the medium, and the incubation was continued for another $20 \mathrm{~h}$ before harvest. Luc enzyme activity was measured by using a Picagene assay kit (Toyo Ink Mfg.). Whole cell extracts (WCEs) were prepared using the lysis buffer supplied by the kit, and enzyme activity was measured according to the manufacturer's instruction $(1 \mu \mathrm{g}$ WCE protein/reaction). For determining CAT and $\beta$ Gal levels, WCEs were prepared as above, and the protein levels were quantified by an enzyme-linked immunosorbent assay (ELISA) using CAT ELISA or $\beta$-Gal ELISA kits (Roche) according to the manufacturer's instructions. All assays were carried out in duplicate.

In HeLa cells transfected with pRSV-Luc, Luc enzyme activity was observed to be markedly increased after exposure to 30 or $50 \mu \mathrm{M} \mathrm{CdSO}_{4}$, as shown in Fig. 2a. $\mathrm{ZnSO}_{4}(200 \mu \mathrm{M})$ also moderately increased Luc activity. By contrast, in cells transfected with pRSV-CAT, the CAT level measured by ELISA was affected little by exposure to $\mathrm{Cd}$ or $\mathrm{Zn}$ at the concentrations described above (Fig. 2b). We also observed that $\beta$ Gal levels measured by ELISA in cells transfected with pRSV- $\beta$ Gal did not respond to $\mathrm{Cd}$ or $\mathrm{Zn}$ either (Fig. 2c). The reproducibility of these results was confirmed by four independent experiments. These data strongly suggest that the target of heavy metals is Luc enzyme activity, rather than RSV promoter.

In order to examine the mechanism by which heavy a

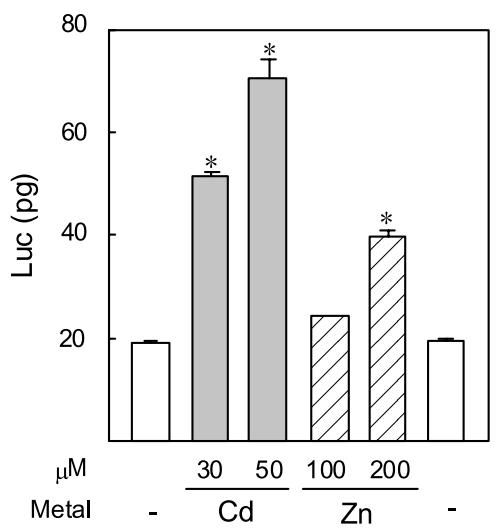

b

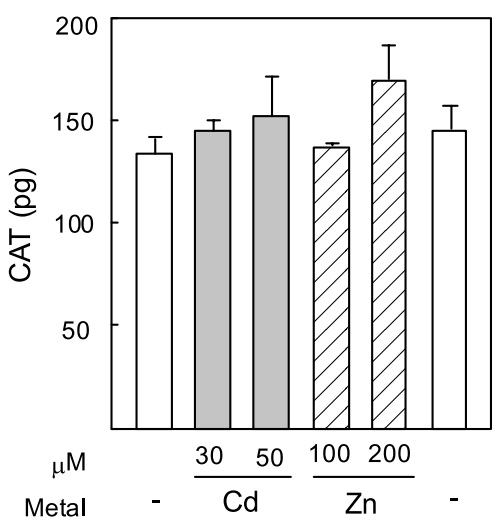

C

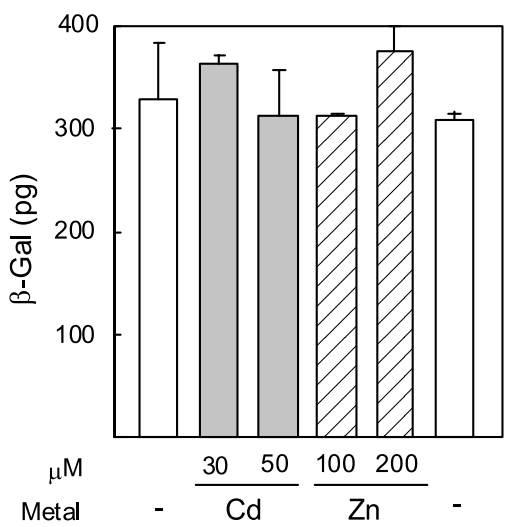

Fig. 2. Heavy metals affect expression of the Luc gene, but not that of the CAT or $\beta$ Gal gene under the same vector background. HeLa cells transfected with pRSV-Luc (a), pRSV-CAT (b) or pRSV- $\beta$ Gal (c) were exposed to the indicated concentrations of CdSO ${ }_{4}$ or $\mathrm{ZnSO}_{4}$ for $20 \mathrm{~h}$, and levels of reporter expression were determined. Open, gray and hatched boxes indicate untreated control cells, Cdtreated cells and $\mathrm{Zn}$-treated cells, respectively. ${ }^{*}, p<0.01$ vs. untreated control. 
a

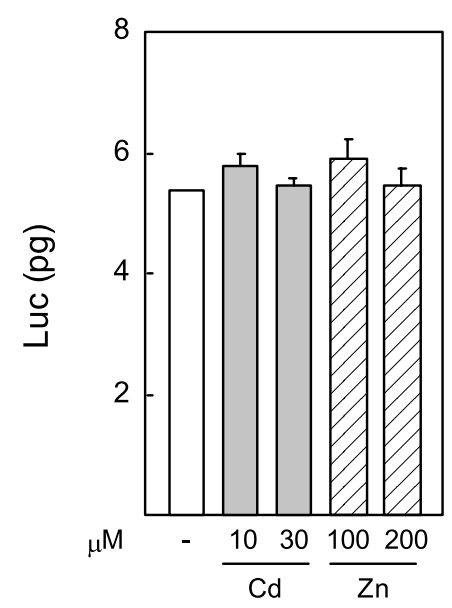

b

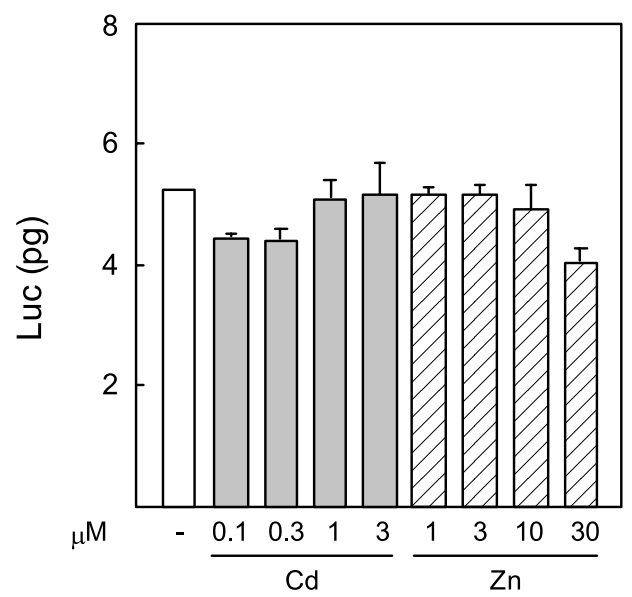

Fig. 3. Heavy metals do not directly affect Luc enzyme activity.

a, Effects of WCEs from heavy metal-treated cells on Luc enzyme activity. b, Effects of heavy metals on Luc enzyme activity.

metals modulate Luc activity, WCEs from heavy metalexposed cells were added to exogenous Luc enzyme (recombinant enzyme used as a standard; supplied by the manufacturer). WCEs $(1 \mu \mathrm{g})$ from cells transfected with pRSV-CAT (i.e. cells not expressing Luc) and exposed to heavy metals were added to Luc enzyme (5 pg), and the mixtures were incubated at $25^{\circ} \mathrm{C}$ for $2 \mathrm{~h}$. As shown in Fig. 3a, WCEs from cells treated with $\mathrm{CdSO}_{4}$ at 10 or $30 \mu \mathrm{M}$, or $\mathrm{ZnSO}_{4}$ at 100 or $200 \mu \mathrm{M}$ did not affect Luc activity. Incubation at higher temperatures $\left(30^{\circ} \mathrm{C}\right.$ or $\left.37^{\circ} \mathrm{C}\right)$ or for a longer period $(6 \mathrm{~h})$ gave similar results (data not shown). We also examined the direct effects of heavy metals on Luc enzyme activity. It is known that the majority of intracellular $\mathrm{Cd}$ is bound by metallothioneins and the level of free $\mathrm{Cd}$ ion is very low ${ }^{13)}$. In this experiment, the effects of $\mathrm{CdSO}_{4}(0.1$ to $3 \mu \mathrm{M})$ and $\mathrm{ZnSO}_{4}$ ( 1 to $30 \mu \mathrm{M}$ ) were evaluated by adding them to the mixture of Luc enzyme and WCE from cells transfected with RSV-CAT and unexposed to metals, and incubating at $25^{\circ} \mathrm{C}$ for $2 \mathrm{~h}$. Also in this experiment, increase of Luc activity as seen in Fig. 2a was not observed (Fig. 3b). These results suggest that heavy metals do not directly affect Luc enzyme activity, but do so through an unknown indirect mechanism in vivo. Because the expression of the CAT or $\beta \mathrm{Gal}$ gene driven by the same RSV-LTR promoter was not influenced by heavy metals (Figs. $2 b$ and 2c), the transcription step does not appear to be the target. Thus, heavy metals might possibly affect a post-transcriptional process. It remains unclear whether the Luc levels determined by ELISA are free from metal effects.

From the present results, we conclude that the use of Luc as a reporter is inappropriate when assessing heavy metal effects, at least under the experimental condition used here. However, we have found a way to circumvent this difficulty, through the use of an alternative reporter, CAT or $\beta \mathrm{Gal}$, which is unaffected by heavy metals. Based on these data, a reliable transfection assay has become available for the study of heavy metal effects. We have been studying the heavy metal responses of human genes utilizing this improved assay6,14). In addition, our results also suggest that when effects of chemicals are evaluated by a transfection assay, it is important to closely inspect their effects on the reporters used in the reporter and reference plasmids prior to starting analysis.

$\mathrm{Cd}$, which was used as a model chemical in the present study, is a well-known toxicant both in general and working environments ${ }^{15}$. Cd accumulates at high concentrations in organs of exposed humans; for example, the kidney cortex of exposed workers has been reported to contain up to $600 \mathrm{mg}$ of $\mathrm{Cd} / \mathrm{kg}^{15}$ ). Although the toxic effect of $\mathrm{Cd}$ is assumed to be mediated by the generation of oxidative stress ${ }^{16)}$, Cd could also exert biological effects by affecting Zn-protein interactions involved in a number of enzymes, transcription factors and so on. An interesting observation of $\mathrm{Cd}$ as an endocrine disruptor ${ }^{17)}$ may possibly be related to its interaction with a zinc-containing estrogen receptor. The improved reporter gene assay established here will be a powerful tool in future studies of the mechanism behind the biological effects of Cd.

\section{References}

1) Otsuka F (2002) Gene expression assay for hazard 
assessment of chemicals. Ind Health 40, 113-20.

2) Koizumi S (1997) Analysis of heavy metal-induced gene expression. In: Handbook of human toxicology, Massaro EJ (Ed.), 103-8, CRC Press, Boca Raton.

3) Yamada H, Koizumi S (2002) DNA microarray analysis of human gene expression induced by a non-lethal dose of cadmium. Ind Health 40, 159-66.

4) Koizumi S, Suzuki K, Ogra Y, Yamada H, Otsuka F (1999) Transcriptional activity and regulatory protein binding of metal-responsive elements of the human metallothionein-IIA gene. Eur J Biochem 259, 635-42.

5) Uenishi R, Suzuki K, Koizumi S (2005) Overexpression of heat shock factor 1 masks the heavy metal response of the heat shock protein 70 (hsp70) gene promoter. J Health Sci 51, 242-7.

6) Koizumi S, Gong P, Suzuki K, Murata M (2007) Cadmium-responsive element of the human heme oxygenase-1 gene mediates heat shock factor 1-dependent transcriptional activation. J Biol Chem 282, 8715-23.

7) Suzuki K, Koizumi S (2000) Individual metal responsive elements of the human metallothionein-IIA gene independently mediate responses to various heavy metal signals. Ind Health 38, 87-90.

8) de Wet JR, Wood KV, DeLuca M, Helinski DR, Subramani S (1987) Firefly luciferase gene: structure and expression in mammalian cells. Mol Cell Biol 7, 725-37.

9) Culotta VC, Hamer DH (1989) Fine mapping of a mouse metallothionein gene metal response element. Mol Cell Biol 9, 1376-80.
10) Westin G, Schaffner W (1988) A zinc-responsive factor interacts with a metal-regulated enhancer element (MRE) of the mouse metallothionein-I gene. EMBO J 7, 3763-70.

11) Gorman CM, Moffat LF, Howard BH (1982) Recombinant genomes which express chloramphenicol acetyltransferase in mammalian cells. Mol Cell Biol 2, 1044-51.

12) An G, Hidaka K, Siminovitch L (1982) Expression of bacterial beta-galactosidase in animal cells. Mol Cell Biol 2, 1628-32.

13) Koizumi S, Otaki N, Kimura M (1985) Evidence for more than two metallothionein isoforms in primates. $\mathrm{J}$ Biol Chem 260, 3672-5.

14) Uenishi R, Gong P, Suzuki K, Koizumi S (2006) Cross talk of heat shock and heavy metal regulatory pathways. Biochem Biophys Res Commun 341, 1072-7.

15) World Health Organization (1992) Environmental Health Criteria 134: Cadmium, World Health Organization, Geneva.

16) Stohs SJ, Bagchi D, Hassoun E, Bagchi M (2001) Oxidative mechanisms in the toxicity of chromium and cadmium ions. J Environ Pathol Toxicol Oncol 20, 77-88.

17) Garcia-Morales $P$, Saceda $M$, Kenney $N$, Kim N, Salomon DS, Gottardis MM, Solomon HB, Sholler PF, Jordan VC, Martin MB (1994) Effect of cadmium on estrogen receptor levels and estrogen-induced responses in human breast cancer cells. J Biol Chem 269, 16896-901. 